\title{
Perfeccionismo e actividade física em adolescentes
}

\section{Perfectionism and physical activity among adolescents}

\author{
M. Pinto, J. Vasconcelos-Raposo, A. Almeida, I. Claro, J. Ledo, M. Marques, C. Teixeira
}

ARTIGO ORIGINAL | ORIGINAL TITLE

\begin{abstract}
RESUMO
O presente estudo visou comparar jovens por sexo, nível de actividade física e fase da adolescência em função dos níveis de perfeccionismo. A amostra foi constituída por 184 indivíduos (96 do sexo feminino) com idades entre os 11 e os 17 anos residentes na região do interior norte Portugal. Foi utilizada a forma Júnior da Escala de Auto-apresentação de Perfeccionismo (PSPS-Jr.). O estudo evidenciou diferenças por níveis de actividade física, grupo etário e sexo. Face aos resultados poderemos concluir que os muito activos pontuam mais alto nas três subescalas do perfeccionismo, que os adolescentes mais jovens se diferenciam na subescala autopromoção e na não-verbalização. As comparações por sexo evidenciam que os indivíduos do sexo masculino apresentam valores mais altos todos os parâmetros avaliados.
\end{abstract}

Palavras-chave: perfeccionismo, actividade física, autopromoção, não-demonstração, não-verbalização

\begin{abstract}
The present study aimed to compare young people by sex, level of physical activity and stage of adolescence according to levels of perfectionism. The sample consisted of 184 individuals (96 female) aged between 11 and 17 years old living in the interior of northern Portugal. The junior form of the Perfectionism Self-Presentation Scale (PSPS-Jr.) was used. The study showed differences by levels of physical activity, age group and sex. In view of the results, we can conclude that the very active score higher in the three subscales of perfectionism that younger adolescents differ in the self-promotion and non-verbalization subscales. Comparisons by sex show that male individuals have higher values for all evaluated parameters.

Keywords: perfectionism, physical activity, self-presentation, body satisfaction
\end{abstract}

Submitted: 07.28.2019 | Accepted: 02.14.2020

Mário Pinto. Assoc. S.Social Via Nova, Vila Real, Portugal

António Almeida, Isabel Claro, Jóni Ledo, Mariana Marques. UTAD, MASSIVE: Health and Performance Psychology Lab. ECT-1, Quinta de Prados, 5000-811 Vila Real, Portugal.

José Vasconcelos-Raposo, Carla M. Teixeira. INESC TEC-MASSIVE, Health \& Performance Psych Lab., Universidade de Trás-os-Montes e Alto Douro, Vila Real, Portugal.

Endereço para correspondência: J. Vasconcelos-Raposo. Health \& Performance Psych Lab. Gab.2.27, ECHS-1. Quinta de 5000881 Vila Real, Portugal.

E-mail: jvraposo@utad.pt 
O perfeccionismo sempre foi visto como sendo apenas um traço estável da personalidade, como sendo bom ou mau e considerava-se uma característica inata na personalidade do sujeito. Enquanto conceito tem-se manifestado importante para melhor perceber as desordens psicológicas. Os estudos que se têm debruçado sobre o perfeccionismo têm tentado desmistificar a separação entre os seus aspectos positivos e negativos, pois se em larga escala o perfeccionismo pode ser muito negativo, também pode ser muito positivo, pois, se tivermos um nível de perfeccionismo não exagerado e se utilizado dentro de certos limites, torna-se uma mais-valia para o desenvolvimento dos indivíduos (Egan, 2005).

Há um crescendo na literatura sobre as investigações que visam identificar e determinar alguns aspectos do perfeccionismo que podem vir a ser importantes para a aplicação clínica. A pesquisa de carácter normativo procura identificar os níveis que podem existir na população em geral, estabelecendo valores critério para se entender até que ponto ele é benéfico ou não, ou quais outras características poderão se detectadas e que devem ser tomadas em consideração pelos profissionais de saúde (Wittenberg \& Norcross, 2001).

O perfeccionismo é tido como uma necessidade compulsiva para atingir metas impossíveis para serem ultrapassadas em qualquer que seja a área de interesse do sujeito. Consiste numa procura inatingível que não e tende a apresentar-se como um desajustamento psicológico, pois querer mais do que aquilo que é possível não se ajusta ao Universo normal do ser humano. Essa busca pelo impossível tende a estar associada a um conjunto de doenças como o stress, a ansiedade, a preocupação com os defeitos, a depressão e o medo de não ser capaz (Silverman, 1999).

Segundo um estudo de Flett, Besser, Davis e Hewitt (2003), foram usados vários testes [Multidimensional Perfectionism Scale (MPS), Unconditional Self-Acceptance Questionnaire e The
Center for Epidemiological Studies Depression Scale (CES-D)], para estudar a forma como as três dimensões do perfeccionismo (auto-orientado, orientado para os outros e perfeccionismo socialmente prescrito) são associados de forma significativa a baixos níveis de auto aceitação e por outro lado, estes níveis de baixa auto aceitação incondicional desencadeiam alguns sintomas depressivos. A auto-aceitação incondicional serve como mediador entre o perfeccionismo socialmente prescrito e a depressão. Este estudo de permitiu uma clarificação do perfeccionismo na incorporação das diferenças individuais no estudo da auto-aceitação incondicional. Segundo Stoeber, Otto e Dalbert (2009) o perfeccionismo socialmente prescrito demonstra correlações positivas com os afectos negativos e outros desajustes psicológicos, tais como a depressão e a ansiedade.

Alguns estudos sobre o perfeccionismo também indicam que este influência as pessoas de forma negativa no seu local de trabalho, pois por vezes pode desencadear comportamentos anormais e consequências muito negativas (Wittenberg \& Norcross, 2001).

O perfeccionismo em relação aos atletas pode revelar benefícios ou efeitos malefícios, dependendo do exagero ou não com que esse perfeccionismo existe e o contexto em que se aplica. Tendo em conta as facetas do perfeccionismo consideradas, os limites a que o indivíduo se propõe, e o exagero pela perfeição, poderão advir relações diferenciais na performance e nas metas estabelecidas (Stoeber, et al., 2008).

O perfeccionismo tem sido abordado em alguns estudos e relacionado com inúmeras situações, como por exemplo, nos atletas de alta competição, em contexto de trabalho, de vergonha, culpa ou orgulho, assim como em outras situações e dimensões afectivas. Um tema que se tem estudado bastante é até que ponto o perfeccionismo deixa de ser saudável e passa a ser prejudicial. Aliás, as opiniões mais antigas apontam mesmo para que os 
perfeccionistas acabem por sentir menos culpa e vergonha e, muitas das vezes, não sintam qualquer orgulho pelos seus comportamentos. Contudo, no estudo de Cruz, Varela e Cabanelas (2010), concluiu-se que isto acaba por se aplicar apenas a "perfeccionistas neuróticos" pois os perfeccionistas normais são pessoas que vivenciam o orgulho, pretendem alcançar sempre níveis mais altos e melhores, mas de uma forma saudável sem se obcecarem por esses mesmos objectivos. Os indivíduos normais e que buscam de forma sistemática a excelência, mesmo em situações de fracasso ou de sucesso vivenciam a culpa ou vergonha e sim pensam nas tarefas que realizaram, nos erros que cometeram, no o que fizeram bem, com a preocupação de identificar o que poderão fazer da próxima vez para poderem melhorar a sua performance numa próxima experiência.

O perfeccionismo começou por fazer parte do desenvolvimento individual, pois uma pessoa saudável tem a ambição e necessidade de obter a realização pretendida, de alcançar os seus objectivos, superar obstáculos e realizar tarefas difíceis que o satisfaçam, sem utilizar métodos desmedidos, para além das suas necessidades. Objectivar sempre mais e melhor torna-se então benéfico para o desenvolvimento humano, considerando-se que ser saudável implica a superação de obstáculos e tarefas difíceis. Nesta perspectiva ser perfeccionista é benéfico para o desenvolvimento do indivíduo (Silverman, 1999).

No estudo de Stoeber, Harris e Moon (2007) foi possível observar uma distinção entre perfeccionistas saudáveis e perfeccionistas não saudáveis que apresentam grandes aspirações mas também grandes preocupações. Os primeiros são indivíduos que apresentam grandes aspirações e poucas preocupações, vivenciam mais o orgulho do que a culpa e vergonha em relação aos segundos.

No estudo de Stoeber, et al., (2008), o perfeccionismo global apresentou correlações positivas tanto com a cognição como com os níveis de ansiedade somática durante o período de competição. Face a estes resultados, a ideia de perfeição no desporto pode ser uma característica disfuncional. Quanto mais focado estiver um atleta num objectivo e quanto mais este pensar no resultado que pretende obter, mais nervoso se sente e consequentemente a sua prestação não será tão eficaz quanto ambicionado. Os atletas perfeccionistas tendem a autoimpor-se níveis elevados de pressão o que os leva a prestações menos bem-sucedidas sendo por isso importante contrariar as tendências perfeccionistas em sujeitos submetidos a elevados rigores de prestação (Flett, Besser, Davis, \& Hewitt; 2003; Stoeber, et al.,, 2007). Mas há quem defenda que o perfeccionismo em atletas, não tem que ser necessariamente negativo, pois tentar estar o mais próximo da perfeição não é um problema, se essa característica não chegar a ser uma disfunção que conduza a comportamentos e ideações obsessivas (Flett, et al., 2003; Stoeber, et al., 2008).

No estudo de Kornblum e Ainley (2005) foram estudados alunos com grandes e pequenas capacidades académicas. Em ambos os casos tipificava-os o terem um espírito perfeccionista. A questão a estudar foi: de que modo aqueles com maiores capacidades se encaixavam nos diferentes tipos de perfeccionismo, saudável e não saudável. Os resultados evidenciaram que os alunos talentosos tinham padrões de perfeccionismo mais elevados do que os não talentosos. Os autores argumentaram que são os alunos perfecionistas com maiores expectativas que outros, e com maiores capacidades académicas os que tendem a observar de uma forma mais realista os seus objectivos, assim como o método e os esforços necessários para alcançar as metas desejadas. Outra evidência constatada foi que os alunos mais competentes têm tendência a apresentar maiores níveis de preocupação com os problemas, devido, talvez, à pressão exercida pelos pais em que eles tinham que se superar. Em relação aos não talentosos, isso já não se 
verificou, pois as suas expectativas também não se encontravam tão elevadas. Os pesquisadores sugeriram que o perfeccionismo se pode considerar como não saudável a partir do momento em que a preocupação com os problemas e o medo de falhar começa a comandar as vidas dos indivíduos perfeccionistas (Kornblum \& Ainley, 2005).

Ao longo dos anos tem-se verificado uma tendência para a realização de padrões de desempenho relacionados com o perfeccionismo. Este traço da personalidade envolve a atenção selectiva, a generalização do fracasso e a auto-avaliação, que levam os indivíduos a pensar da forma "tudo-ou-nada", ou seja, não podem obter resultados medianos, preferem ficar aquém das expectativas justificando as suas prestações como uma casualidade, uma excepção à regra. Utilizando esta perspectiva do "tudo-ou-nada" podemos obter diferentes justificações para os resultados de sucesso ou de fracasso (Kornblum \& Ainley, 2005). Ainda na opinião dos mesmos autores, muitas vezes os atletas tendem a querer ser perfeccionistas e acabam por se deixar levar para um mundo onde a oportunidade de regressar à normalidade escasseia, pois devido a fenómenos como a ansiedade acabam por falhar os seus objectivos e ficar deprimidos.

Como pudemos ver, o perfeccionismo está presente em tudo o que nos rodeia, trabalho, desporto, as próprias relações afectivas em que exigimos que o outro seja perfeito, assim como em muitos outros cenários da vida.

Segundo Silverman (1999) o perfeccionismo é uma das características individuais mais incompreendidas. Podemos verificar duas formas de perfeccionismo a nível de expectativas, aquele em que é o próprio indivíduo que se torna cada vez mais perfeccionista, que luta pela excelência e pela busca da realização pessoal. Por outro lado, existe também a pressão exercida pelos outros para que o sujeito em causa atinja determinados objectivos. Este segundo tipo de perfeccionismo já não é considerado saudável (Silverman, 1999). Estes comportamentos foram estudados por vários autores, nomeadamente Stirling e Kerr (2006) e Cruz, et al., (2010). Ambos os estudos analisaram o padrão de relações entre perfeccionismo, ansiedade física e social, percepção de ameaça e auto-apresentação em atletas de competição e em praticantes regulares/amadores de exercício, tendo sempre em conta as pressões exercidas quer pelos próprios atletas, quer pelos pais ou treinadores (Stirling, \& Kerr, 2006; Cruz, et al., 2010).

Os padrões de exigência podem ser devidos a critérios pessoais, que correspondem a expectativas do próprio e a critérios interpessoais que são estabelecidos ou esperados pelos outros (Cruz, et al., 2010). Quando analisados os estudos verificou-se que a pressão dos pais e dos treinadores tem resultados mais negativos relativamente aos benefícios para os atletas. A pressão é demasiadamente elevada para permitir que os indivíduos obtenham bons resultados, ou, mesmo obtendo bons resultados, a percepção de orgulho e sensação de bem-estar não é tão grande como quando são os próprios a quererem obter os melhores resultados (Stirling, \& Kerr, 2006; Cruz, et al., 2010).

Tendo em conta o perfeccionismo em especialistas, no estudo de Wittenberg e Norcross (2001), que estudou os psicólogos, relacionando-os com a sua vertente perfeccionista, verificou-se que os psicólogos mais velhos são, geralmente, menos perfeccionistas. Verificou-se também que o perfeccionismo social tende a estar associado com a satisfação no trabalho.

Uma das escalas mais importantes desenvolvidas nesta área de estudo ao perfeccionismo é a "Multidimensional Perfectinism Scale" (MPS; Frost, Martens, Lahart e Rosenblate (1990). É uma escala que mede seis dimensões distintas relativas a características perfeccionistas, sendo os padrões pessoais, a preocupação com os erros, as expectativas dos pais, as dúvidas existentes acerca das acções, o criticismo parental 
e a organização as variáveis mais criticas (Cruz, et al., 2010). Mais tarde desenvolveu-se uma segunda medida de avaliação global das dimensões do perfeccionismo, quer sejam inter ou intrapessoais. Também esta escala foi desenvolvida com base no MPS, apenas com uma particularidade, esta medida foi dividida em três séries, cada uma delas avaliando a sua área, nomeadamente o perfeccionismo auto-orientado, o perfeccionismo orientado para os outros e o perfeccionismo socialmente prescrito (Cruz, et al., 2010).

Posteriormente foi desenvolvido um novo instrumento de avaliação das características perfeccionistas dos atletas, "Sport Multidimensional Perfectionism Scale" (SMPS). Este instrumento foi desenvolvido por Dunn et al. (2002; 2006) e é constituído por 35 itens (Cruz, et al., 2010).

Mais recentemente foi desenvolvido o (PI) "Perfectionism Inventory" por Hill, et al. (2004). Este instrumento pretende avaliar o perfeccionismo considerado saudável ou consciencioso, tendo em conta quatro dimensões diferentes, tais como o planeamento, a organização, os elevados padrões para os outros e a luta pela excelência (Cruz, et al., 2010).

Apesar de toda a aproximação entre termos como excelência e perfeccionismo, na verdade é que nem sempre são considerados sinónimos. Mas na verdade, estes termos devem ser separados, pois perfeccionismo é a não-aceitação de qualquer resultado que não seja considerado perfeito, algo que não o seja torna-se inaceitável quando se fala em excelência. Isto por que apenas se torna necessário obter um resultado suficiente, que seja razoavelmente aceitável, e que não tem de ser perfeito. A pessoa que procura a excelência é capaz de se sentir orgulhoso e satisfeito com uma prestação razoável, que não seja má, mas que represente um momento de avaliação positiva dos progressos feitos, enquanto que um sujeito perfeccionista necessita que tudo o que faz seja perfeito, exemplar e não simplesmente bom.
Segundo Silverman (1999) existem cinco níveis de perfeccionismo. O primeiro corresponde à ausência de um controle total das tarefas, manifestam-se na forma de desejos em se ser melhor, mas estes não atingem uma dimensão que acaba por controlar a vida do indivíduo. Num segundo nível verificam-se formas rudimentares de perfeccionismo, o indivíduo quer mudar para melhor, pretende obter melhores resultados podendo mesmo gerar obsessões e fobias, o sujeito que se encontre no nível 2 tende a apresentar ansiedade excessiva e torna-se rígido para consigo e com os outros. No nível 3 o indivíduo predominantemente pensa que pode viver de forma muito melhor, vislumbra um ideal de personalidade, quando vive um momento extremamente bom e depois, quando essa sensação passa, sente-se fracassado e passa a viver momentos de tormento. O nível 4 , significa que os sujeitos se empenham e têm força de vontade para obterem os resultados desejados e têm a capacidade de manifestar compaixão por eles próprios e pelos demais, conseguindo partilhar vitórias, não esperam que os bons resultados sejam valorizados só pelo seu empenho, mas admitem e valorizam a cooperação dos outros para os sucessos que alcançam. Num último nível, correspondendo ao nível 5, os sujeitos obtêm uma harmonia com os demais, consideram-se perfeccionistas saudáveis, sem prejudicarem a sua saúde nem a dos outros, lutam pelo que querem, mas no limite do saudável (Silverman, 1999).

Para este estudo tivemos em conta a existência de três dimensões do perfeccionismo; a "autopromoção do perfeccionismo" que consiste no facto de os indivíduos valorizarem as suas conquistas, lutarem pelo desejado, mostrarem aquilo em que são melhores, evidenciando como todos estes parâmetros se apresentam benéficos ao self individual de cada sujeito. De seguida temos a "não-demonstração do imperfeccionismo", ou seja, os sujeitos considerados perfeccionistas têm vergonha em mostrar aos demais os seus erros e sentem pânico só de imaginar 
a possibilidade de falhar perante alguém. Não muito longe desta não- demonstração dos erros, encontramos um terceiro parâmetro, a "não-verbalização do imperfeccionismo". Isto é, o sujeito perfeccionista até pode errar, não pode é ser descoberto, este é um dos grandes medos dos perfeccionistas, que os seus pontos fracos sejam descobertos, daí só destacarem e falarem das suas vitórias e de tudo fazerem para esconder aquilo em que não são tão bons. Uma outra estratégia é procurarem evitar determinadas situações que os poderiam diminuir de um estatuto percebido como exemplar (Caelian, Papsdorf, Cassels, \& Birch, 2010).

Estes comportamentos relativos ao perfeccionismo são mais facilmente visíveis em indivíduos que são sujeitos a grandes níveis de stresse ou ansiedade e que se encontram sob grande pressão (Silverman, 1999). Eventualmente esta é uma das razões por que uma percentagem elevada de estudos sobre o perfeccionismo tenha como amostras atletas ou outras áreas sujeitas a avaliações com base na performance obtida.

No presente estudo temos como objectivos específicos comparar por níveis de actividade física, fase da adolescência e sexo em função das três dimensões do perfeccionismo: autopromoção, não-demonstração e não-verbalização do perfeccionismo.

\section{MÉTODOS}

Este estudo é de natureza quase-experimental, comparativo e transversal. A variável dependente nesta investigação é o perfeccionismo e as variáveis independentes são a prática de actividade física e a prática de desporto.

\section{Amostra}

A amostra deste estudo foi constituída por 184 indivíduos, dos quais $52.2 \%(\mathrm{~N}=$ 96) são do sexo feminino e $47.8 \%(\mathrm{~N}=88)$ do sexo masculino. Todos eles têm idades compreendidas entre os 11 e 17 anos. Os inquiridos são provenientes do interior norte de Portugal e na sua maioria habitando em zonas rurais $(\mathrm{N}=130)$.

Os praticantes de desporto participam em campeonatos escolares, inicialmente a nível regional e posteriormente a nível nacional, incluindo nesta prática os treinos semanais de pelo menos dois dias e provas ocasionais nas respectivas modalidades. Para os praticantes de actividade física definiu-se como critério que os participantes exercessem alguma actividade de lazer realizada de forma livre, duas ou mais vezes por semana. Para os propósitos deste estudo não forma consideradas as actividades laborais ou domésticas. Tendo em conta a idade dos sujeitos, criámos dois grupos, o primeiro correspondente à adolescência inicial, indivíduos dos 11 aos 14 anos e o segundo corresponde à adolescência média, sujeitos com mais de 15 anos. Uma vez que na nossa amostra não se incluem adolescentes com mais de 17 anos não fazemos alusão à adolescência final.

\section{Procedimentos}

Para a aplicação dos questionários solicitou-se a autorização aos Conselhos Directivos das escolas envolvidas na recolha da amostra. Após a obtenção das respostas demos início à distribuição dos questionários. Os mesmos foram confiados aos Treinadores Desportivos e Professores de Educação Física juntamente com uma explicação acerca da natureza de cada questão, assim como sobre os objectivos do estudo em geral.

\section{Instrumentos}

Para a realização deste estudo foi utilizado o Perfectionistic Self-Presentation Scale-Junior Form (PSPS-Jr). A tradução e adaptação do PSPS-Jr foram feitas em duas fases. A primeira envolveu uma explicação cuidadosa acerca da informação a que se vai aceder, bem como o treino sobre o implícito em cada um dos itens. Os itens foram, posteriormente, verificados para não haver qualquer tipo de falha, como 
por exemplo na repetição de itens ou uso de gramática imprópria. A segunda fase envolveu a selecção dos itens analisados (Caelian, Papsdorf, Cassels, \& Birch, 2010).

O PSPS-Jr é composto por 18 itens correspondentes a várias facetas do perfeccionismo. Cada participante responde com base numa escala de 5 pontos de Likert que varia entre 1 (de maneira alguma) e 5 (extremamente) (Caelian, et al., 2010).

Para procedermos à introdução dos dados relativos à amostra e posterior análise estatística utilizámos o software Statistical Package for Social Sciences (SPSS 20.0). De modo a analisar e testar os objectivos de estudo procedeu-se ao calculo da média, desvio-padrão, máximo e mínimo para todas as variáveis. Quanto à consistência interna e à sua determinação procedemos ao cálculo do coeficiente de homogeneidade através do procedimento Reability Analysis do programa estatístico SPSS 20.0.

\section{Procedimentos Estatísticos}

Procedeu-se à análise de variância univariada para estabelecer as comparações das variáveis em estudo. Para as comparações por sexo e grupo etário usou-se o T-test. De modo a testar as hipóteses inerentes aos nossos objectivos específicos utilizámos as provas estatísticas, Independent Sample T-test, Oneway Anova e teste Post Hoc de Scheffe e Tamhane do SPSS 16.0.

O coeficiente de alpha de Cronbach e respectiva consistência interna para a escala na sua integra foi de .871 e as sub-escalas apresentaram valores de .422 (apenas com quatro itens) para a não-verbalização, .69 para não-demonstração e .852 para a autopromoção.

\section{RESULTADOS}

Através da análise das respostas aos itens relativos ao perfeccionismo verificou-se que a maioria dos jovens obteve níveis mais elevados de autopromoção no perfeccionismo ( $\mathrm{M}=$ 22.00) do que nos restantes que dizem respeito ao facto de não mostrar $(M=19.96)$ e não verbalizar $(\mathrm{M}=11.88)$ o imperfeccionismo, como podemos observar no quadro 1, destacando ainda os valores de Skewness e Kurtosis permitindo-nos permitem recorrer a uma estatística paramétrica.

Quadro 1

Análise descritiva dos itens do PSPS-Jr

\begin{tabular}{lccccc}
\hline \multicolumn{1}{c}{ Itens do PSPS-jr } & Mínimo & Máximo & Média \pm DP & Skewness & Kurtosis \\
\hline $\begin{array}{l}\text { Autopromoção do } \\
\text { perfeccionismo }\end{array}$ & 9 & 35 & $22.00 \pm 5.68$ & -.094 & -.214 \\
$\begin{array}{l}\text { Não-Demonstração do } \\
\text { imperfeccionismo }\end{array}$ & 9 & 30 & $19.96 \pm 4.30$ & .145 & .013 \\
$\begin{array}{l}\text { Não-Verbalização do } \\
\text { imperfeccionismo }\end{array}$ & 6 & 20 & $11.88 \pm 2.67$ & .227 & .274 \\
\hline
\end{tabular}

Relativamente ao nível de Actividade Física, verifica-se que os rapazes (26\%) são muito activos, quando comparados com as raparigas (17\%), mostrando-se estas mais inactivas (6\%). As mulheres são mais activas (29\%) do que os homens $(20 \%)$. Ao nível da inactividade as mulheres representam $6 \%$ e os homens $2 \%$ da amostra, assim como é maior o número de mulheres inactivas $(6 \%)$ quando comparadas com os homens.
Quando se comparam os níveis de Actividade Física em função das dimensões do perfeccionismo, verifica-se que os indivíduos muito activos têm uma maior autopromoção para o perfeccionismo e apenas este se mostra estatisticamente significativa, $F_{(2,181)}=5.71, p=.004$. Ainda assim, os sujeitos inactivos $(\mathrm{M}=24.27)$ têm níveis mais elevados de autopromoção do perfeccionismo que os activos $(M=23.63)$. 
$10 \mid$ M. Pinto, et al.

Quadro 2

Niveis de Perfeccionismo e Niveis de Actividade Física (ANOVA e testes Scheffe e Tamhane).

\begin{tabular}{lccccc}
\hline \multicolumn{1}{c}{$\begin{array}{c}\text { Dimensões do } \\
\text { Perfeccionismo }\end{array}$} & $\begin{array}{c}\text { Inactivos } \\
(\mathrm{G} 1, n=15) \\
\mathrm{M} \pm \mathrm{DP}\end{array}$ & $\begin{array}{c}\text { Activos } \\
(\mathrm{G} 2, \boldsymbol{n}=90) \\
\mathrm{M} \pm \mathrm{DP}\end{array}$ & $\begin{array}{c}\text { Muito Activos } \\
(\mathrm{G} 3, n=79) \\
\mathrm{M} \pm \mathrm{DP}\end{array}$ & $F$ & Dif. G. \\
\hline $\begin{array}{l}\text { Autopromoção do } \\
\text { Perfeccionismo }\end{array}$ & $24.27 \pm 3.34$ & $23.63 \pm 5.58$ & $26.77 \pm 6.97$ & $5.71^{* *}$ & \\
$\begin{array}{l}\text { Não Demonstração do } \\
\text { Imperfeccionismo }\end{array}$ & $20.67 \pm 3.33$ & $19.50 \pm 3.87$ & $20.90 \pm 6.39$ & 1.67 & \\
$\begin{array}{l}\text { Não Verbalização do } \\
\text { Imperfeccionismo }\end{array}$ & $11.06 \pm 2.08$ & $11.58 \pm 2.43$ & $12.30 \pm 2.92$ & 2.28 & $\mathrm{G} 3>\mathrm{G} 1>\mathrm{G} 2$ \\
\hline
\end{tabular}

${ }^{* *} p<.01$.

Quadro 3

Dimensões do Perfeccionismo e Fases da Adolescência (Teste t).

\begin{tabular}{lccc}
\hline \multicolumn{1}{c}{ Dimensões do Perfeccionismo } & $\begin{array}{c}\text { Adol. Inicial } \\
(\boldsymbol{n}=94) \\
\mathbf{M} \pm \mathrm{DP}\end{array}$ & $\begin{array}{c}\text { Adol. Média } \\
(\boldsymbol{n}=90) \\
\mathbf{M} \pm \mathrm{DP}\end{array}$ & $t$ \\
\hline Autopromoção do Perfeccionismo & $26.17 \pm 6.07$ & $26.17 \pm 6.07$ & $2.56^{*}$ \\
Não-Demonstração do Imperfeccionismo & $20.84 \pm 4.22$ & $19.81 \pm 5.88$ & 1.00 \\
Não-Verbalização do Imperfeccionismo & $2.29 \pm 2.71$ & $11.40 \pm 2.51$ & $2.30^{*}$ \\
\hline
\end{tabular}
${ }^{*} p<.05 ;{ }^{* *} p<.01 ;{ }^{* * *} p<.001$.

A autopromoção do perfeccionismo manifesta-se mais nos indivíduos que se encontram na adolescência inicial $(p=.011)$. Também é na fase inicial da adolescência que se verificaram valores mais elevados na não-demonstração do imperfeccionismo $(p=.023)$, revelando uma diferença estatisticamente significativa.

Quadro 4

Dimensões do Perfeccionismo e Género (Teste t).

\begin{tabular}{|c|c|c|c|}
\hline Dimensões do Perfeccionismo & Sexo $(N)$ & $\mathrm{M} \pm \mathrm{DP}$ & $t$ \\
\hline \multirow{2}{*}{ Autopromoção do Perfeccionismo } & Masculino (88) & $26.56 \pm 6.5$ & \multirow{2}{*}{$3.25^{* *}$} \\
\hline & Feminino (96) & $23.64 \pm 5.69$ & \\
\hline \multirow{2}{*}{ Não-Demonstração do Perfeccionismo } & Masculino (88) & $20.53 \pm 5.94$ & \multirow{2}{*}{.86} \\
\hline & Feminino (96) & $19.89 \pm 4.18$ & \\
\hline \multirow{2}{*}{ Não-Verbalização do Perfeccionismo } & Masculino (88) & $12.43 \pm 2.63$ & \multirow{2}{*}{$2.90^{*}$} \\
\hline & Feminino (96) & $11.32 \pm 2.57$ & \\
\hline
\end{tabular}

Quando se comparam as dimensões do perfeccionismo sexo verificamos que o sexo masculino apresenta maiores índices em todos os parâmetros, sendo as diferenças estatisticamente significativo na autopromoção do perfeccionismo ( $p=.001)$ e na não-verbalização do imperfeccionismo $(p=.004)$.

$p<.05 ;^{* *} p<.01 ;^{* * *} p<.001$.

\section{DISCUSSÃO}

Em relação ao presente estudo, de natureza exploratória, foram elaboradas várias hipóteses tendo por base as diferenças entre níveis de actividade física fase da adolescência e diferenças por seco. As análises estatísticas levadas a cabo permitiram rejeitar cinco hipóteses nulas. Verificou-se que a amostra apresenta níveis elevados de perfeccionismo, revelando níveis mais reduzidos no facto de não mostrar e não-verbalizar o imperfeccionismo. Esta é uma característica 
saudável do perfeccionismo, pois estes demonstram mais as características positivas ligadas a este, do que as características negativas que são evidenciadas quando não mostram ou não-verbalizam o imperfeccionismo (Caelian et al., 2010). Os níveis de perfeccionismo são sempre distintos de pessoa para pessoa, sendo que existem inúmeras características e práticas que podem alterar os níveis de perfeccionismo, pois em atletas de alto rendimento é, geralmente, evidenciado um maior perfeccionismo, sendo que estes, revelando-se como os melhores entre os melhores têm que tentar a perfeição para conseguir os seus objectivos (Cruz, et al., 2010). Estes resultados vão de encontro aos verificados no nosso estudo, pois os indivíduos mais activos fisicamente demonstram-se como mais perfeccionistas.

No estudo de Stoeber et al. (2007), os perfeccionistas saudáveis são também caracterizados por terem mais orgulho de que vergonha e preocupação, ou seja, o contrário do que acontece com os outros tipos de perfeccionismo. $\mathrm{Na}$ presente investigação verificou-se que, de facto, os indivíduos mais perfeccionistas têm também valores mais elevados para mostrarem aquilo que fazem bem e sentirem orgulho das suas tarefas bem realizadas do que para esconder o imperfeccionismo. Ou seja, mesmo os erros que cometem, são vivenciados como momentos de orgulho pelo facto de terminarem as suas tarefas com sucesso e não como situações geradoras de vergonha e humilhação aquando do insucesso.

Neste estudo observamos, com uma diferença estatisticamente significativa, que os indivíduos do sexo masculino praticam mais actividade física do que os do sexo feminino. Esta diferença na prática de actividade física pode advir de vários factores, como por exemplo uma maior tendência dos jovens do sexo masculino para ocupar o seu tempo livre com práticas desportivas, dando assim forma à sua competitividade, e valorização do corpo, como forma perfeccionista. Para além disso a prática parece estar intimamente associada a uma das suas formas para promover o convívio, sendo que as raparigas tendem a socializar de uma maneira mais sedentária. Estes resultados vão de encontro ao estudo de Filipe (2007) onde também se verificou que os indivíduos do sexo masculino são mais activos, independentemente da sua idade ou estatuto social. A literatura sugere que para a maioria das pessoas o motivo para praticarem actividade física é a preparação física e as práticas corporais associadas com a imagem corporal, tal como esta é promovida pela sociedade em que as pessoas se inserem.

A prática de actividade física moderada, em qualquer idade é positiva para a saúde, pois desta advêm inúmeros ganhos positivos para a saúde. No estudo agora elaborado, para além de se verificar que a actividade física é positiva para a saúde, é também explicitado que os indivíduos que praticam actividade física se percepcionam como mais saudáveis do que aqueles que não praticam. Estes resultados reforçam a máxima de que a actividade física não só traz benefícios físicos, como também psicológicos, sendo verificável através das relações, descritas na literatura da especialidade, entre a prática de actividade física e o perfeccionismo saudável ou autopromoção do perfeccionismo, tal como foi constatado no presente estudo.

No que diz respeito à satisfação corporal, os resultados evidenciam percepções semelhantes, pois os indivíduos que praticam mais actividade física apresentam, de forma significativa, maior satisfação com o seu corpo do que os que não praticam. Tendo em conta estes resultados, podemos fazer alusão ao estudo de Kornblum e Ainley (2005), onde se provou que indivíduos mais activos provaram ser mais perfeccionistas e percepcionam-se de forma mais saudável que os restantes. No estudo de Cruz et al. (2010) comprovou-se, também, que a prática desportiva influencia positivamente a percepção corporal e consequente bem-estar com o self. Segundo Filipe. S (2007), as mulheres têm uma tendência para valorizar a imagem corporal, sendo que esta valorização (busca pelo perfec- 
cionismo) é ligeiramente superior e só é visível em mulheres com menos de 40 anos de idade. Tal constatação leva-nos a crer que a satisfação corporal (perfeccionismo) também perde a sua importância à medida que a idade vai avançando, sendo os 40 anos apontado como um ponto de viragem, mas para o qual não se encontram evidências científicas. No caso do nosso estudo analisamos apenas uma amostra de indivíduos jovens, não sendo, por isso, possível retirar o mesmo tipo de conclusões. $\mathrm{Na}$ ausência de estudos sobre esta temática entre os mais jovens, apenas podemos referir, que nas camadas jovens, os indivíduos mais activos fisicamente, também têm uma percepção de si mais positiva.

Quando a comparação foi feita entre actividade física e os níveis de perfeccionismo, ficou patente que os indivíduos que praticam mais actividade física tendem a ser mais perfeccionistas do que os indivíduos que praticam menos, o que leva a crer que a prática de actividade física em níveis considerados (activos e muito activos), esta associado, entre os jovens, a maiores preocupações a nível do perfecionismo do que aqueles que são menos activos. No contexto do desporto, quando a actividade física é levada mais a sério, quando todas as características e os pequenos detalhes são a preocupação central, por serem percepcionadas como aquelas que decidem o desfecho de uma competição, os indivíduos tendem a ser mais perfeccionistas, tanto na própria competição como nos treinos que a antecedem tendo em vista uma superação pessoal (Cruz, et al., 2010).

Os indivíduos mais novos (adolescência inicial) apresentam níveis mais altos de autopromoção do perfeccionismo, sendo este nível de perfeccionismo o mais saudável. Importa, ainda, tomar em consideração que é também nestes grupos etários que mais se esconde o imperfeccionismo, que é visto como uma característica negativa do perfeccionismo. A preocupação com a comparação social faz com que os jovens levem demasiado a sério o erro, e evita- -se falar dele e a demonstrá-lo à frente de outras pessoas. A competição desportiva regular (comparativamente ao exercício), promovem não só maiores preocupações com a auto-apresentação e com a percepção de ameaça, mas também maiores orientações perfeccionistas, seja ao nível das pressões percebidas, ou ao nível dos padrões de exigência pessoal e das preocupações com o rendimento (Cruz, et al., 2010). Um facto interessante é que os indivíduos na fase da adolescência inicial condensam em si tanto os aspectos positivos como os negativos em relação ao perfeccionismo, o que leva a acreditar que a adolescência leva os jovens a terem medo e vergonha de falhar, principalmente quando essa falha é presenciada por outras pessoas.

Tendo em consideração que o sexo masculino apresentou níveis mais elevados de perfeccionismo do que o sexo feminino, no que diz respeito a autopromoção do perfeccionismo e à não-verbalização do imperfeccionismo, o que nos faz admitir que os rapazes são, por norma, mais perfeccionista do que as raparigas, e que têm mais vergonha em admitir as suas falhas perante os outros. Este facto supõe-se que seja consequência de os rapazes praticarem mais actividade física e serem mais competitivos, levando a competição muito mais a sério, enquanto as raparigas praticam actividade física mais por uma questão de satisfação corporal do que por questões subjacentes à competição.

Como a influência da actividade desportiva no perfeccionismo e os estudos nesta área ainda são recentes, não há muita material para se poder analisar e fazer inferências e identificar possíveis erros na forma como se tem abordado a problemática aqui em causa. No mesmo sentido, sendo a palavra "perfeccionismo" tão vasta e por vezes até desconhecida enquanto fenómeno psicológico, torna-se também difícil estudar este tema. No entanto, o método por nós utilizado e aplicado numa população jovem foi bem-sucedido. Esta é uma área que ainda tem muito para se descobrir e discutir. A forma 
como os jovens das sociedades actuais se auto-avaliam e se recriam influencia os seus níveis de perfeccionismo. É, então, do interesse geral que os níveis de perfeccionismo sejam os adequados, de modo a que os jovens se mantenham saudáveis e para tal deverão ser contempladas intervenções especificamente dirigidas a esta temática.

Estes estudos requerem, no futuro, um maior aprofundamento, visto que o perfeccionismo no contexto da prática de actividade física e no desporto se apresenta como sendo da maior importância. É, por isso, fundamental, para perceber até que ponto as estas práticas encaminham ou não os jovens até determinados níveis de perfeccionismo e de que modo isso os influencia no dia-a-dia e como podem contornar possíveis disfunções relacionadas com o medo de fracassar, a vergonha e as sensações de desvalorização quando não se encontra o procurado.

Para um melhor estudo sobre este assunto dever-se-á ter em conta que, nem sempre, ser perfeccionista é saudável pois, como se verificou, existem perfeccionistas não saudáveis, tendo sentimentos associados com a não-demonstração e não-verbalização do imperfeccionismo. Estes indivíduos tendem a revelar maiores níveis de ansiedade o que, consequentemente, afecta as suas relações sociais. Num estudo que envolva o perfeccionismo e a actividade física será sempre essencial ter em conta questões como o tipo de actividade física que praticam, a frequência de prática e as diferenças entre sexos, e contexto sociocultural onde se inserem. Só com as análises multifactoriais se obterá uma compreensão mais profunda e abrangente acerca deste tema, pela razão simples de que se estudarmos o perfeccionismo desconsiderando os factores que lhe estão subjacentes não poderemos ter dados suficientes para construir uma teoria eficaz para explicar este fenómeno do comportamento humano.

\section{CONCLUSÃO}

Obtivemos resultados significativos, nomea- damente no que respeita à forma como os indivíduos se vêem e se percepcionam a si próprios em função das variáveis em estudo.

Os sujeitos muito activos apresentam valores mais altos nas três subescalas quando comparados com os activos e inactivos. As comparações por grupo etário evidenciaram que os que se encontram na fase inicial da adolescência se diferenciam estatisticamente, ao pontuarem mais alto na subescala auto-promoção do perfeccionismo e mais baixo na não-verbalização do imperfeccionismo.

Apesar de não se abordar uma população muito abrangente, conclui-se que muitos jovens se percepcionam de forma positiva, o que permite inferir que estes demonstram saúde, como também uma auto-estima e bem-estar saudáveis.

\section{Agradecimentos: \\ Nada declarado.}

\section{Conflito de Interesses:}

Nada declarado.

\section{Financiamento:}

Nada declarado.

\section{REFERÊNCIAS}

Caelian, C., Papsdorf, M., Cassels, T., \& Birch, S. (2010). Perfectionism self-presentation in children an adolescents: development and validation of the perfectionism selfpresentation scale - junior form. American Psychology Association, doi: 10.1037/ a0021147

Cruz, J. F. A., Varela, I., \& Cabanelas, S. (2010). Perfeccionismo, auto-apresentação e ansiedade na competição desportiva e na prática de exercício: Estudo exploratório com atletas de competição e praticantes de exercício (pp. 1925-1941). Actas do VII Simpósio Nacional de Investigação em 
psicologia. Portugal: Escola de Psicologia, Universidade do Minho.

Dunn, J. G., Gotwals, J., Dunn, J.C., \& Syrotuik, D. (2006). Examining the relationship between perfectionism and trait anger in competitive sport. International Journal of Sport and Exercise Psychology, 4(1), 7-24. doi.org/10.1080/16 12197X.2006.9671781

Dunn, J.G., DUnn, J. C., \& Syrotuik, D. (2002). Relationship between multidimensional perfectionism and goal orientation in sport. Journal of Sport \& Exercise Psychology, 24(4), 376-395. doi.org/10.1123/ jsep.24.4.376

Egan, J. S. (2005). An investigation of positive and negative perfectionism. Curtin University of Technology School of Psychology.

Filipe, S. (2007). O caso do Health Club PapaStress na Vila da Batalha. Monografia de Licenciatura realizada no âmbito do Seminário de Sociologia do Desporto. Universidade de Coimbra.

Flett, G. L., Besser A., Davis, A. R., \& Hewitt, P., L. (2003). Dimensions of perfectionism, unconditional self-acceptance, and depression. Journal of Rational-Emotive $\mathcal{E}$ Cognitive-Behavior Therapy, 21 (2): 119-138. Doi: 10.1023/A:1025051431957

Frost, R., Marten, P., Lahart, C., \& Rosenblade, R. (1990). The dimensions of perfectionism. Cognitive Therapy and Research, 14(5), 449-468.

Hill, R., Hueslman, T., Furr, R., Kibler, J., Vicente, B., \& Kennedy, C. (2004). A new measure of perfectionism: The perfectionism inventory. Journal of Personality Assessment, 82(1), 80-91. DOI: $10.1207 /$ s15327752jpa8201_13
Kornblum, M., \& Ainley, M. (2005). Perfectionism and the gifted: A study of an Australian school sample. International Education Journal, 6(2), 232-239.

Silverman, L. (1999). Perfectionism: The crucible of giftedness. Advanced Development, 8, 47-61.

Stirling, A., \& Kerr, G. (2006). Perfectionism and mood states among recreational and elite athletes. The Online Journal of Sport Psychology, 8(4), 13-27.

Stoeber, J., Harris, R. A., \& Moon, P. S. (2007). Perfectionism and the experience of pride, shame, and guilt: Comparing healthy perfectionists, unhealthy perfectionists, and nonperfectionists. Personality and Individual Differences, 43(1), 131-141.

Stoeber, J., Otto, K. \& Dalbert, C. (2009). Perfectionism and the Big Five: Conscientiousness predicts longitudinal increases in self-oriented perfectionism. Personality and Individual Differences,47, 363-368.

Stoeber, J., Stollb, O., Pescheckb, E., \& Ottoc, K. (2008). Perfectionism and achievement goals in athletes: Relations with approach and avoidance orientations in mastery and performance goals. Psychology of Sport and Exercise, 9, 102-121.

Wittenberg, K. J., \& Norcross, J. C. (2001). Practitioner perfectionism: relationship to ambiguity tolerance and work satisfaction. Journal of Clinical Psychology, 57(12), 15431550. 